\title{
Risco Social na Região Imediata de Campina Grande: subsídios para a compreensão das condições socioambientais
}

\author{
Social Risk in the Immediate Region of Campina Grande: subsidies for the \\ understanding of socio-environmental conditions
}

\begin{abstract}
Riesgo Social en la Región Inmediata de Campina Grande: subsidios para la comprensión de las condiciones socio ambientales
\end{abstract}

\author{
Amanda Alves Queiroga ${ }^{1}$ \\ Maiane Barbalho da $\mathrm{Luz}^{2}$ \\ Camila Cunico ${ }^{3}$
}

\begin{abstract}
RESUMO: A ocupação de áreas impróprias à habitação pela parcela mais pobre da população tem ocasionado uma maior exposição desta aos desastres provenientes de fenômenos naturais. $O$ trabalho buscou caracterizar o risco social na Região Imediata de Campina Grande, na Paraíba, com o intuito de fornecer subsídios que auxiliem na gestão e planejamento ambiental da região. Foram integrados indicadores sociais e econômicos (renda per capita mensal abaixo de um salário mínimo, população total e domicílios sem abastecimento de água pela rede geral, entre outros) para elaboração de mapas, de modo a compreender o risco social. Os indicadores foram escolhidos para analisar o contexto social e econômico, além da privação de serviços essenciais. O risco social foi categorizado em "muito baixo", "baixo", "moderado", "alto" e "muito alto". A parte leste da região apresentou uma maior concentração de municípios de "muito alto" a "alto" risco social. A parte oeste mostrou-se bastante heterogênea, predominando municípios em situação de "baixo" risco social. A pesquisa realizada em escala regional fornece aporte para efetuar novos estudos em uma escala intraurbana, assim os gestores dos municípios poderão obter os resultados como uma contribuição para tomada de decisão, avaliando as áreas mais vulneráveis aos desastres.
\end{abstract}

PALAVRAS-CHAVE: Desastres naturais. Paraíba. Planejamento regional.

ABSTRACT: The occupation of inappropriate areas to dwelling by the poorest part of the population has caused a greater exposure of this population to disasters from natural phenomena. Therefore, this

\footnotetext{
${ }^{1}$ Universidade Federal da Paraíba. Departamento de Engenharia Civil e Ambiental. Cidade Universitária, s/n - Castelo Branco III, João Pessoa - PB, 58051-085 - amandaaqueiroga@gmail.com.

2 Universidade Federal da Paraíba. Departamento de Engenharia Civil e Ambiental. Cidade Universitária, s/n - Castelo Branco III, João Pessoa - PB, 58051-085 - maianebarbalho07@gmail.com.

${ }^{3}$ Universidade Federal da Paraíba. Departamento de Geociências. Cidade Universitária, s/n - Castelo Branco III, João Pessoa - PB, 58051-085 camilacunico@yahoo.com.br.
} 
Risco Social na Região Imediata de Campina Grande: subsídios para a compreensão das condições...

study sought characterizes the social risk in the Immediate Region of Campina Grande, in Paraíba, in order to provide subsidies which assist in the environmental management and planning of the region. These subsidies were inserted into social and economic indicators (per capita monthly income below a minimum wage, total population, and households without water supply through the general network, among others) for elaboration of maps, in order to comprehend the social risk. Indicators were chosen to analyze the social and economic context, besides the deprivation of essential services, which are submitted to the population. The social risk was categorized in "very low", "low", "moderate", "high" and "very high". The eastern part of the region showed a greater concentration of counties with "very high" to "high" social risk. On the other hand, the western part was very heterogeneous, predominating counties in situation of "low" social risk. The research accomplished in a regional scale provides contribution to effect new studies in an intraurban scale, thus, managers of the counties will can obtain results as cooperation for decision-making, evaluating the most vulnerable areas to disasters.

KEY WORDS: Natural disasters. Paraíba. Regional planning.

RESUMEN: La ocupación de áreas impropias para la habitación por una parcela más pobre de la población ha ocasionado una mayor exposición de ésta a los desastres provenientes de fenómenos naturales. Siendo así, el presente trabajo buscó caracterizar el riesgo social en la Región Inmediata de Campina Grande, en Paraíba, con el intuito de proveer subsidios que auxilien en la gestión y planeamiento ambiental de la región. Fueron integrados indicadores sociales y económicos (renta per cápita mensual por debajo de un salario mínimo, población total, domicilios sin abastecimiento de agua por la red general, entre otros) para elaboración de mapas, a modo de comprender el riesgo social. Los indicadores fueron escogidos para analizar el contexto social y económico, además de la privación de servicios esenciales, que están sometidos a la población. El riesgo social fue categorizado en "muy bajo", "bajo", "moderado", "alto" y "muy alto". La parte este de la región presentó una mayor concentración de municipios de "muy alto" a "alto" riesgo social. La parte oeste se mostró bastante heterogénea predominan municipios en situación de "bajo" riesgo social. La investigación realizada a escala regional proporciona aporte para efectuar nuevos estudios en una escala intraurbana, así, los gestores de los municipios podrán obtener los resultados como una contribución para la toma de decisiones, evaluando las áreas más vulnerables a los desastres.

PALABRAS-CLAVE: Desastres naturales. Paraíba. Planeamiento regional.

\section{INTRODUÇÃO}

O aumento da urbanização tem causado uma expansão da população para porções dos municípios que não deveriam ser habitadas. Esses locais, desprezados pelo mercado imobiliário, em função de falta de estrutura urbana, mostram-se como a alternativa mais viável para a habitação da parcela menos favorecida da sociedade.

A ausência de fiscalização nessas áreas e a deficiência na gestão territorial permitem que esses locais sejam cada vez mais ocupados, de forma desordenada e caótica, sem nenhum planejamento. Esses locais, em sua grande maioria, apresentam condições sanitárias inadequadas, com ausência de serviços de água e esgoto e disposição 
inadequada de resíduos sólidos, entre outros problemas que tornam a vida da população mais suscetível a veiculações de doenças e acidentes.

A problemática das mudanças climáticas atinge todas as pessoas, no entanto, a população de baixa renda é a parcela da população mais duramente afetada pela sua menor capacidade de reação aos eventos extremos. Sem poder aquisitivo relevante para lidar com os danos causados pelos desastres, somado com as áreas de alto risco ambiental em que se encontram, as consequências desses desastres são então potencializadas.

Em 2017, o Instituto Brasileiro de Geografia e Estatística propôs um novo modelo de Divisão Regional do Brasil em Regiões Geográficas Imediatas e Regiões Geográficas Intermediárias, levando em consideração os conceitos de território-rede (considerando os fluxos que ocorrem) e território-zona (considerando o controle exercido pelas cidades, mediante suas funções e atividades de alcance intra-regionais e inter-regionais) (IBGE, 2017c). A área de estudo, Região Geográfica Imediata de Campina Grande, abrange 47 municípios, estando 42 deles inseridos na região do semiárido paraibano. O semiárido paraibano apresenta vários fatores que permitem a formação de uma predisposição do meio natural à ocorrência de eventos naturais perigosos, principalmente derivados da inconstância da pluviosidade na região. Esses fatores são ainda mais agravados mediante intervenções antropogênicas em ambientes extremamente vulneráveis. O uso de métodos e técnicas que auxiliem na identificação dessas áreas mais vulneráveis pode ser uma importante ferramenta para prevenção de desastres e também para promover programas e projetos que ajudem na adaptação e resiliência pós-desastre.

Um dos instrumentos de análise de risco mais utilizados e eficientes é o mapeamento de áreas de risco. Por meio da sua classificação, esse instrumento proporciona uma base de dados para gestão de desastres, possibilitando uma visão abrangente, oferecendo subsídios para o planejamento e ações preventivas. Mediante o conhecimento das áreas que apresentam maior risco, torna-se possível a elaboração de medidas que possam reduzir o impacto do desastre para a população.

Diante do exposto, o objetivo da pesquisa é mapear as áreas com maior risco social na Região Geográfica Imediata de Campina Grande, considerando aspectos sociais e econômicos. Logo, o presente estudo poderá subsidiar futuros estudos sobre a vulnerabilidade socioambiental na região, colaborando para identificar os municípios mais vulneráveis aos desastres provenientes de fenômenos naturais.

\section{PRESSUPOSTOS TEÓRICOS}

O crescimento das cidades não proporcionou simultaneamente um desenvolvimento da infraestrutura urbana, diminuindo assim a capacidade de aproveitamento do espaço, 
Risco Social na Região Imediata de Campina Grande: subsídios para a compreensão das condições...

restringindo a saúde ambiental, proporcionando serviços urbanos mal ofertados, afetando consequentemente a qualidade de vida da população e degradando o meio ambiente.

Com a ausência de infraestrutura adequada para suportar essa expansão urbana, um grande contingente populacional tende a se estabelecer em áreas de risco ambiental, pois são as mais acessíveis a essas populações, como áreas de várzeas com baixa declividade, encostas de morros, áreas de preservação ambiental e áreas junto ao leito dos rios e mais próximas da costa (TORRES, 1997).

Torres et al. (2003) cita três diferentes grupos de causas para a concentração espacial de populações pobres nas periferias e favelas: o mercado de trabalho e a estrutura social; a dinâmica do mercado imobiliário e de produção de moradias; e as políticas estatais. No primeiro grupo o autor enfatiza a estrutura econômica do capitalismo de países em desenvolvimento. No segundo, ele cita que o mercado imobiliário tem o poder de controlar as melhores localizações e especular com terras desocupadas, mecanismos de valorização de terra, de modo que esses fatores causam a segregação das pessoas com menor poder aquisitivo por meio da competição pelo uso de terra. Sobre as políticas estatais o autor cita como fatores influentes o aumento do valor da terra em algumas partes da cidade devido a investimentos públicos ou de obras públicas que podem deslocar alguns grupos sociais ou até mesmo a ação direta do Estado de retirar as populações de baixa renda dos locais em que elas estão inseridas.

O contexto social é de fundamental importância para entender a vulnerabilidade de forma abrangente e não pontualmente, visto que as condições em que a população está inserida são determinantes para a sua resiliência aos desastres.

Segundo Veyret (2007), para a compreensão do risco e da percepção que se tem dele, deve ser considerado o contexto histórico que o produziu, bem como as relações com o espaço geográfico, os modos de ocupação do território e as relações sociais. Não há risco sem uma população ou indivíduo que o perceba e que possa sofrer seus afeitos adversos.

Os riscos devem ser tratados como o resultado da interação entre ameaça e vulnerabilidade, que possuem uma forte ligação entre si. A ameaça está vinculada às condições físico-naturais da área ocupada, indicando o grau de suscetibilidade à ocorrência de fenômenos que podem proporcionar uma situação de perigo ao grupo inserido naquele ambiente, como escorregamentos, inundações e secas, entre outros. Já a vulnerabilidade se refere a diversas características da sociedade que causam a predisposição dos grupos sociais de sofrer danos frente ao impacto de um evento físico externo e que dificultam a adaptação pós-desastre (LAVELL, 1999).

Egler (1996) afirma que o risco social é resultante das carências sociais perante o desenvolvimento humano que contribuem para a degradação das condições da população. Manifesta-se na ausência das condições mínimas para uma boa qualidade de vida, como o 
acesso a serviços básicos tais como água tratada, esgotamento sanitário e coleta de resíduos.

A interação entre as abordagens social e ambiental do risco permite identificar a relação entre a sociedade e a natureza e o resultado dessa interação proporciona o reconhecimento da vulnerabilidade socioambiental do local. Esse discernimento permite uma maior eficiência no gerenciamento de riscos, na tentativa de minimizar os impactos gerados, por meio da elaboração de políticas públicas que auxiliem a população em relação à resiliência e capacidade adaptativa aos desastres.

\section{CARACTERIZAÇÃO DA REGIÃO GEOGRÁFICA IMEDIATA DE CAMPINA GRANDE}

O IBGE, em 2017, estabeleceu um novo modelo de divisão regional. As regiões são classificadas agora em Regiões Geográficas Imediatas e Regiões Geográficas Intermediárias. A Paraíba é composta por quatro Regiões Geográficas Intermediárias (Campina Grande, João Pessoa, Patos e Sousa-Cajazeiras) e por 16 Regiões Geográficas Imediatas (IBGE, 2017c).

A Região Geográfica Intermediária de Campina Grande comporta quatro Regiões Geográficas Imediatas: Campina Grande, Cuité-Nova Floresta, Monteiro e Sumé, abrangendo, assim, uma quantidade de 72 municípios. A Região Geográfica Imediata de Campina Grande comporta em sua totalidade 47 municípios (Figura 1).

Figura 1 - Mapa da Região Geográfica Imediata de Campina Grande
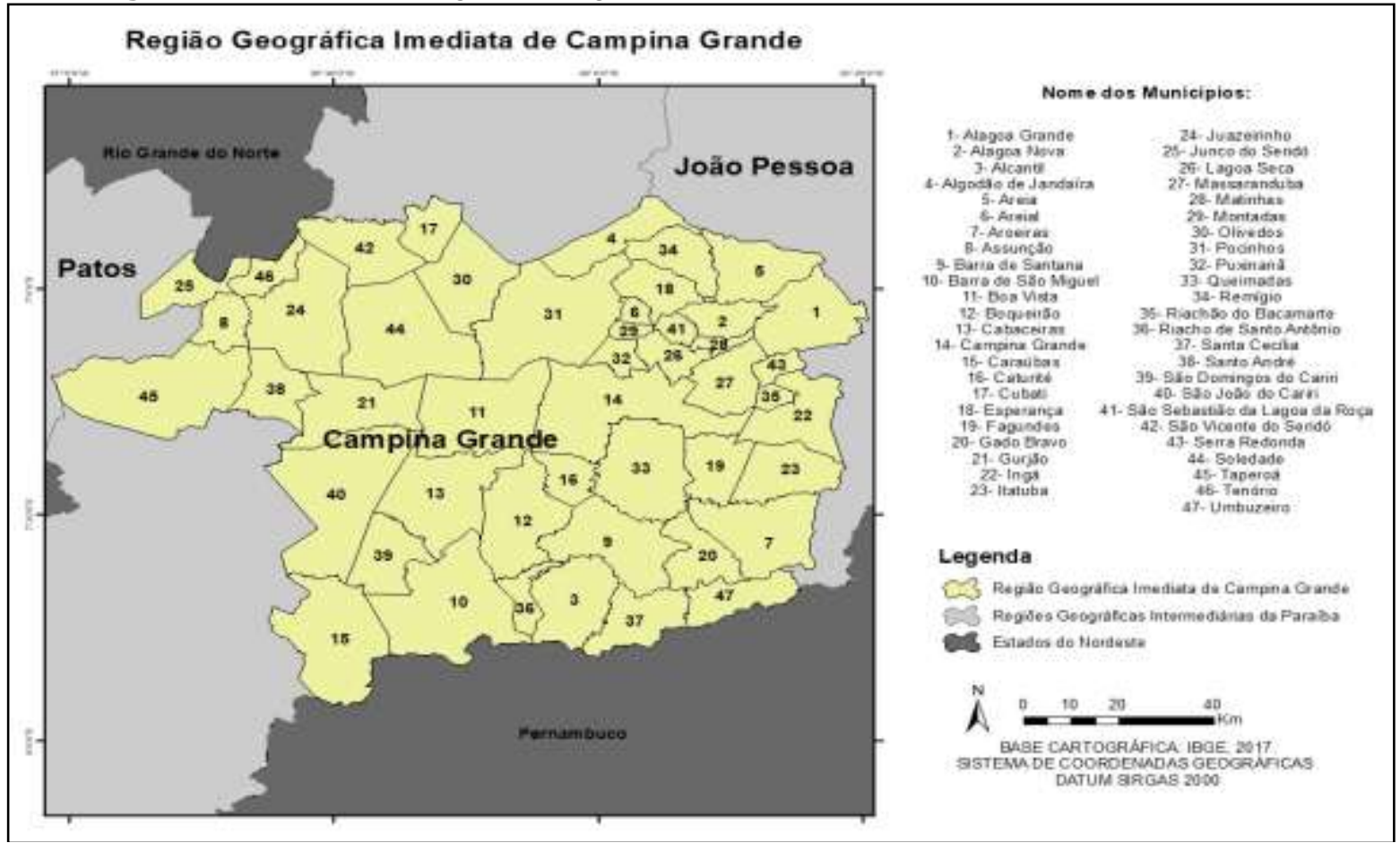

Fonte: organizado pelos autores de IBGE (2017c). 
Risco Social na Região Imediata de Campina Grande: subsídios para a compreensão das condições...

Segundo o IBGE (2017a), a população estimada para essa região em julho de 2017 foi de 939.661 habitantes distribuído em uma área total de 12.695 .644 quilômetros quadrados. A cidade com maior número de habitantes da região nesse ano é Campina Grande. A segunda e a terceira cidade mais populosa são Areia e Queimadas. As três menos populosas são Santo André, Algodão de Jandaíra e Riacho de Santo Antônio.

Dos 47 municípios que compõem a Região Geográfica Imediata de Campina Grande, 42 fazem parte da região semiárida do país, que ao todo é formada por 1.189 municípios de nove estados: Alagoas, Bahia, Ceará, Minas Gerais, Paraíba, Pernambuco, Piauí, Rio Grande do Norte e Sergipe.

A região semiárida do Nordeste é uma das áreas mais vulneráveis às variações climáticas devido às chuvas irregulares, deficiência hídrica, baixa capacidade de adaptação e pobreza extrema. Acrescenta-se a isso o ciclo forte de estiagens e secas que atingem a região, em intervalos que podem durar poucos ou muitos anos. Isso corrobora para piorar ainda mais as frágeis condições de vida de pequenos produtores e outros grupos mais pobres da região (MARENGO, 2008).

Segundo o Atlas Brasileiro de Desastres Naturais, no volume que se refere ao estado da Paraíba, um estudo realizado pela UFSC-CEPED, os municípios mais afetados por secas e estiagens da Região Geográfica Imediata de Campina Grande foram Camalaú, Alcantil, Pocinhos, Esperança e Remígio, registrando de 13 a 15 ocorrências no período de 1991 a 2010 (UNIVERSIDADE FEDERAL DE SANTA CATARINA, 2011).

$A$ irregularidade das chuvas influencia nas atividades agropastoris, base da economia local. A ausência de infraestrutura de adaptação ao clima e gerência dos recursos hídricos acaba afetando a atividade econômica no semiárido. A população explora os recursos naturais até a exaustão das terras, seja por esgotamento do solo por causa do uso intensivo ou instalação de processos erosivos devido à remoção da cobertura vegetal e salinização, ocasionando problemas como a desertificação (OLIVEIRA et al, 2009).

\section{METODOLOGIA}

Os Sistemas de Informações Geográficas têm sido utilizados por vários setores quando se refere a questões ambientais por se tratar de uma ferramenta importante para o planejamento ambiental, permitindo uma abrangente avaliação por meio da integração de diversas variáveis que podem ser espacializadas de forma rápida e simples.

Para analisar as condições sociais e econômicas da população foram utilizados dados do Censo Demográfico de 2010 realizado pelo Instituto Brasileiro de Geografia e Estatística (IBGE, 2011). Os dados foram manipulados e organizados, a fim de somar as informações 
de cada setor censitário do município para obter finalmente as informações deste em sua totalidade.

Os dados utilizados foram relacionados às condições do entorno dos domicílios (domicílios que não possuem energia elétrica, domicílios sem abastecimento de água pela rede de distribuição e domicílios sem coleta de lixo), condições sociais (população total do domicílio e população analfabeta) e condições econômicas (domicílios que possuem uma renda per capita mensal abaixo de um salário mínimo). O salário mínimo em 2010 era de $\mathrm{R} \$$ 510,00. O intuito da escolha dessas variáveis é avaliar quais municípios tem um menor acesso a alguns dos serviços mais essenciais para uma boa qualidade de vida, apresentando uma maior situação de risco.

Os mapas foram elaborados utilizando o software ArcGis 10.2, versão free trial. $O$ método de classificação utilizado para a elaboração dos mapas foi o método estatístico quantile. Os quantis são medidas separatrizes que dividem os dados de forma ordenada em partes iguais, de forma que haja a distribuição do mesmo número de feições para cada classe.

Para melhor compreender a análise dos dados, é necessário distinguir média de mediana. A média é a soma de todos os valores da variável, dividida pela frequência total. Já a mediana é o valor que ocupa a posição central na distribuição de frequências - ela é calculada com base na ordem dos valores que formam o conjunto de dados (GUIMARÃES, 2008).

O valor da média é uma informação importante para entender o comportamento dos dados em uma escala intraregional, pois ela permite a comparação dos dados dos municípios com o valor médio da região, analisando a variação que ocorre.

Foram adotadas cinco classes para distribuição dos valores e posterior espacialização dos dados. Por dividir a série em cinco classes, a medida separatriz denominada quintil permite que cada classe fique com $20 \%$ de seus elementos, de forma que a mediana esteja localizada no centro, ou seja, na terceira classe. O primeiro quintil separa a sequência ordenada, deixando $20 \%$ dos seus valores à esquerda e $80 \%$ de seus valores à direita. De modo análogo são definidos os outros quintis (RIBEIRO, 2015).

Os procedimentos metodológicos adotados para identificar as áreas com maior risco social foram adaptados dos pressupostos utilizados por Alves (2006) e Alves e Torres (2006). Como as características variam de região para região, optou-se por adaptar essa metodologia partindo da suposição que as dimensões escolhidas serão mais adequadas à realidade local.

Os resultados foram obtidos por meio da integração dos dados sociais e econômicos, mediante a confecção de mapas, buscando espacializar essas informações. O levantamento desses dados permitiu a avaliação da realidade em que a população está inserida. 
Risco Social na Região Imediata de Campina Grande: subsídios para a compreensão das condições...

\section{RESULTADOS E DISCUSSÕES}

A ausência de serviços básicos de infraestrutura geralmente pode caracterizar aglomerados subnormais, onde vivem pessoas que tem precárias condições de habitação e proteção social, o que torna essas pessoas mais vulneráveis aos desastres relacionados aos fenômenos naturais. As áreas ocupadas por esses grupos na grande maioria das vezes são áreas consideradas impróprias para ocupação urbana pela legislação urbanística e ambiental, porque podem oferecer risco ambiental, ou ainda serem áreas de preservação permanente. Assim, de acordo com o IBGE (2011) entende-se por aglomerado subnormais unidades habitacionais carentes, em sua maioria de serviços públicos essenciais, ocupando ou tendo ocupado, até período recente, terreno de propriedade alheia (pública ou particular) e estando dispostas, em geral, de forma desordenada e densa.

A população do município é fator relevante para a compreensão do risco. A presença de chuvas de intensa e curta duração características da região resulta em enchentes, inundações e deslizamentos de encostas, que são associadas ao adensamento urbano não planejado. Quanto maior a pressão exercida pela urbanização no local, maior será a movimentação da população mais pobre para áreas mais afastadas, que apresentam maior risco e estão mais expostas ao perigo. A distribuição da população da Região Imediata de Campina Grande é apresentada na Figura 2.

De acordo com o mapeamento temático elaborado, os nove municípios mais populosos localizam-se na parte leste da região, são eles: Campina Grande, Queimadas, Esperança, Alagoa Grande, Lagoa Seca, Areia, Alagoa Nova, Aroeiras e Ingá. É importante destacar a cidade de Campina Grande, a mais populosa da região, pois existe uma grande discrepância entre o seu número de habitantes (383.710 habitantes) e o número de habitantes de Queimadas (segunda mais populosa da região, com 41.015 habitantes).

Campina Grande é a segunda cidade mais populosa da Paraíba, ficando atrás apenas da capital paraibana, João Pessoa. É considerada um dos principais polos industriais e tecnológicos do Nordeste e destaca-se a sua importância econômica e política no estado. Segundo o Instituto de Desenvolvimento Municipal e Estadual (IDEME), Campina Grande, durante os anos 2013 e 2014, foi responsável pelo segundo maior PIB do estado, representando cerca de aproximadamente $15 \%$ do total das riquezas produzidas na Paraíba (PARAÍBA, 2016).

Então, notou-se que pelo fato de Campina Grande apresentar uma maior população quando comparada a outros municípios da Região Imediata de Campina Grande, elevou o valor da média dos dados de forma que a média de habitantes foi para 18.853 habitantes. A média enquadrada na quinta classe constata que esse valor não reflete a realidade local, 
visto que 39 municípios tem um total de habitantes abaixo desse valor da média obtido. Essa discrepância será observada em todos os outros mapas, onde a média sempre será um pouco maior devido a elevados valores dos dados da cidade de Campina Grande.

Figura 2 - Mapa de População da Região Geográfica Imediata de Campina Grande

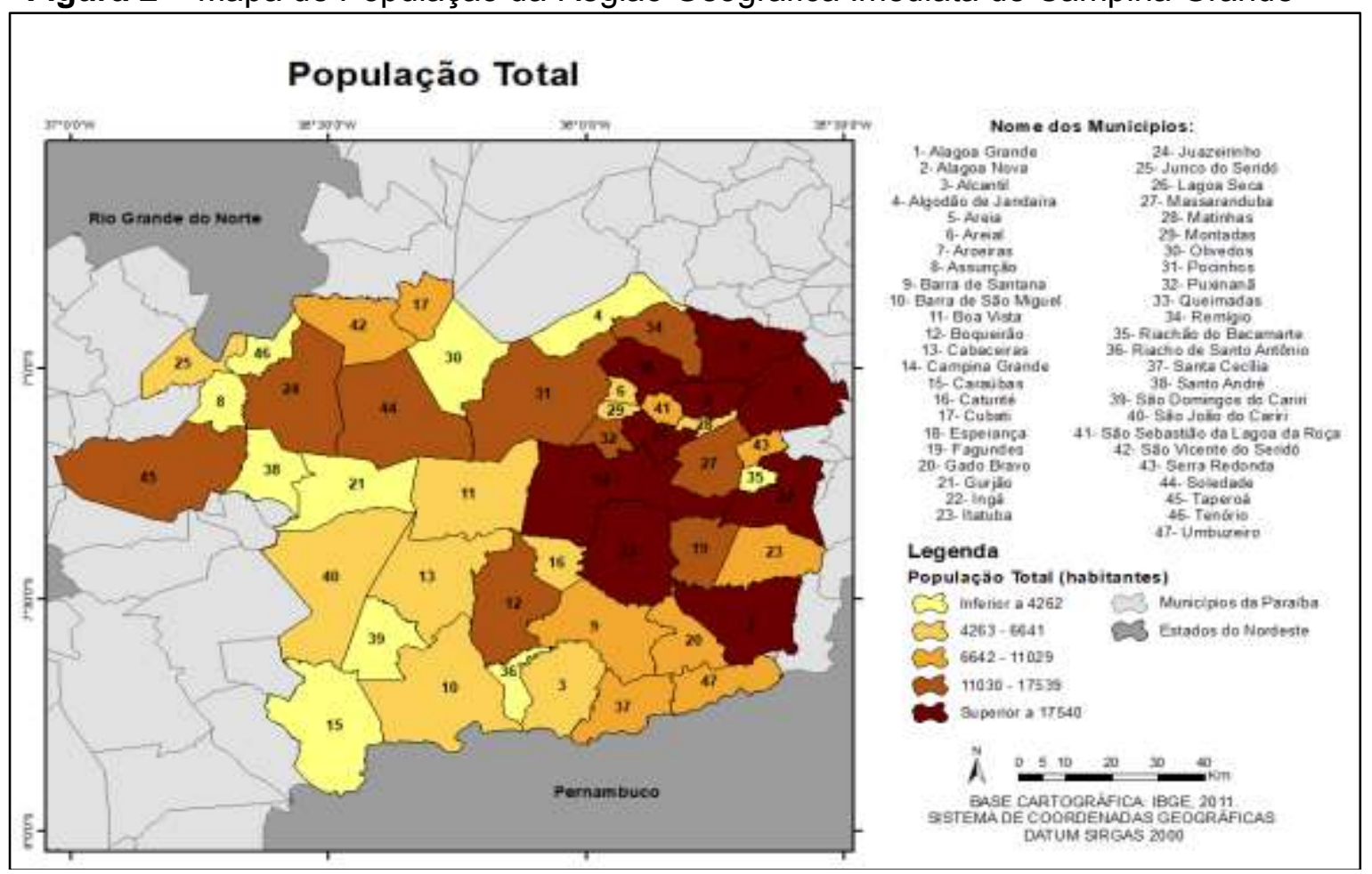

Fonte: organizado pelos autores de IBGE (2011).

A parte menos populosa da região localiza-se mais ao sul, de forma que o município com menos habitantes é Riacho de Santo Antônio, apresentando 1.713 habitantes. É interessante observar que nem sempre municípios com grandes áreas territoriais são municípios populosos, como São João do Cariri (4.336 habitantes) e Barra de São Miguel (5.604 habitantes).

Segundo a nova proposta de classificação e caracterização dos espaços urbanos e rurais realizada pelo IBGE, $76,5 \%$ dos municípios da Região Geográfica Imediata de Campina Grande são unidades populacionais que apresentam de baixo a moderado grau de urbanização. Esse estudo levou em consideração os seguintes critérios: população em áreas de ocupação densa, proporção da população em áreas de ocupação densa em relação à população total e localização. Apenas Campina Grande, Lagoa Seca, Massaranduba, Puxinanã, Queimadas e Remígio são municípios predominantemente urbanos. Os municípios de Alagoa Grande, Areia, Boqueirão, Esperança e Ingá são considerados intermediários, com um moderado grau de urbanização (IBGE, 2017b).

Durante o período de 2014 a 2017, Campina Grande e mais 16 municípios da Região Imediata de Campina Grande (Queimadas, Lagoa Seca, Alagoa Nova, Pocinhos, Boqueirão, 
Risco Social na Região Imediata de Campina Grande: subsídios para a compreensão das condições...

Juazeirinho, São Sebastião da Lagoa da Roça, São Vicente do Seridó, Barra de Santana, Cubati, Boa Vista, Cabaceiras, Caturité, Matinhas e Olivedos) sofreram racionamento de água devido à incapacidade hídrica dos açudes. Em uma região semiárida, marcada pela seca, os açudes passaram por períodos de escassez, prejudicando a qualidade de vida da população.

A presença do abastecimento de água em um local é imprescindível, pois quando implementado demonstra uma melhoria na saúde e nas condições de vida da população, tendo como consequência uma diminuição na incidência de doenças de veiculação hídrica. A falta de condições adequadas de saneamento básico, principalmente relacionada à água e esgotamento sanitário, é uma das principais causas da mortalidade infantil.

Um estudo feito por Mendonça e Motta (2007) demonstrou que os gastos defensivos de saúde apresentam custos equivalentes aos gastos relacionados com a expansão dos serviços de saneamento. Portanto, os serviços de saneamento promovem uma significativa diminuição de riscos das doenças e ainda possuem externalidades positivas ao meio ambiente que não foram contabilizadas no estudo.

A ausência de abastecimento de água influi nas condições de salubridade ambiental em que a população vive. Com a carência desse serviço, além da vulnerabilidade a doenças, as condições podem ser agravadas caso venha a ocorrer um evento extremo, comprometendo a saúde e bem-estar da população. O mapa da quantidade de domicílios não abastecidos por água da rede distribuidora é apresentado na Figura 3.

A região leste se destaca pela concentração de municípios que apresentam maior quantidade de domicílios sem abastecimento de água pela rede distribuidora. Lagoa Seca é o município que apresenta mais domicílios sem abastecimento pela rede, compreendendo 3.915 domicílios nessa situação, cerca de $15 \%$ do total de domicílios da cidade. Aroeiras foi o segundo município com mais domicílios com essa condição (3.270 domicílios, 62,6\% do total de domicílios da cidade). O município que apresenta menor número de domicílios sem esse tipo de abastecimento é Riacho de Santo Antônio, com apenas 185 domicílios nessa situação, sendo $39 \%$ do total de domicílios da cidade. A média da quantidade de domicílios que possuem essa forma de abastecimento de água foi de 1.392 domicílios.

A média de domicílios localizou-se na quarta classe, situação ocasionada devido à discrepância de muitos domicílios em municípios muito urbanizados e municípios rurais com poucos domicílios. O elevado número de domicílios em municípios com um grande número de habitantes elevou a média, não podendo esta ser utilizada como parâmetro para avaliação da região como um todo, por causa da sua condição heterogênea.

Campina Grande apresentou 2.509 domicílios sem abastecimento pela rede, valor acima da média (1.932 domicílios) quando comparado aos outros municípios, mas sabendose a elevada população que essa cidade possui também quando comparada aos outros 
municípios, é um valor baixo, apresentando apenas $2,2 \%$ do total de domicílios da cidade nessa condição.

Figura 3 - Mapa dos domicílios sem abastecimento de água pela rede de distribuição na Região Geográfica Imediata de Campina Grande

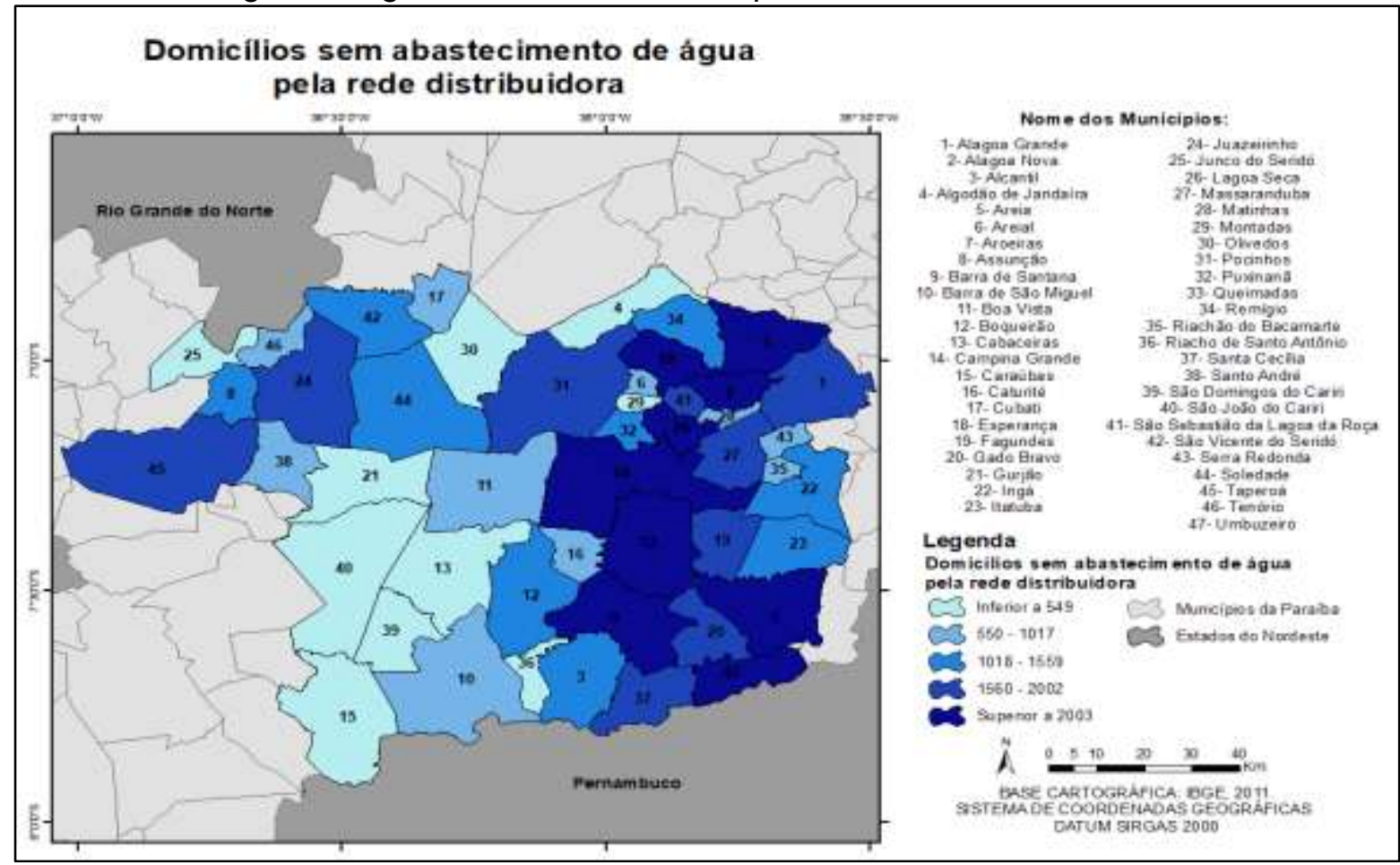

Fonte: organizado pelos autores de IBGE (2011).

As outras formas de abastecimento de água que possuem informações no Censo Demográfico do IBGE são: abastecimento por água de poço ou nascente da propriedade, abastecimento da água da chuva armazenada em cisternas e outras formas de abastecimento não identificadas.

Os municípios com a maior porcentagem de seus domicílios abastecidos por água da chuva armazenada em cisternas, de acordo com o mapeamento elaborado, foram Matinhas $(38,8 \%)$ e Gado Bravo (38,1\%). Já os municípios com a maior porcentagem de seus domicílios abastecidos por água de poço ou nascente da propriedade foram Matinhas $(18,8 \%)$, Areia $(17,3 \%)$ e Alagoa Nova (16,7\%). Outras formas de abastecimento não identificadas apresentam porcentagens mais elevadas nos municípios. Nove municípios apresentam mais da metade de seus domicílios utilizando abastecimento de água por outras fontes não identificadas: Assunção (97\%), Tenório (83,5\%), Alcantil $(78,2 \%)$, Santa Cecília (70,1\%), Santo André (69,6\%), Algodão de Jandaíra (67,9\%), Umbuzeiro (60\%), Barra de Santana (53\%) e Caturité $(50,4 \%)$.

Um problema identificado no semiárido é que, embora haja uma grande quantidade de recursos hídricos subterrâneos, a água obtida apresenta uma grande concentração de sais. 
Risco Social na Região Imediata de Campina Grande: subsídios para a compreensão das condições...

Os municípios que não possuem abastecimento de água da rede distribuidora podem adquirir água de outras fontes, buscando alternativas para a escassez de água superficial na região por meio da captação da água da chuva por cisternas ou ainda dessalinização de água subterrânea.

Além disso, existem municípios da região aonde a água chega aos domicílios unicamente por meio de carros-pipa, tais como: Riacho de Santo Antônio, Aroeiras, Gado Bravo, Puxinanã, Barra de Santa Rosa, Algodão de Jandaíra, Areial e Montadas. Municípios como Alagoa Grande, Alagoa Nova, Areia, Matinhas, Serra Redonda e São Vicente do Seridó eram abastecidos por meio de carros pipa até o final de 2017.

Em relação aos resíduos sólidos, muitos municípios da Paraíba ainda possuem lixões a céu aberto, contrariando a Política Nacional dos Resíduos Sólidos, instituída pela Lei Federal no 12.305/10 (BRASIL, 2010), que discorre sobre a disposição e destinação adequada dos resíduos e rejeitos gerados nos municípios.

A disposição inadequada dos resíduos sólidos provoca sérios impactos ambientais, sociais e de saúde pública. O chorume é gerado a partir da decomposição do lixo e, além de produzir odores indesejáveis, também produz metano que faz parte de gases do efeito estufa. Outro problema da disposição inadequada é a proliferação de animais e microrganismos que podem transmitir doenças para a população.

Portanto, a ausência de coleta de lixo também é um fator que pode mensurar a salubridade ambiental da área. A disposição inadequada ainda pode obstruir galerias, ocasionando alagamentos e potencializando as consequências de um desastre em épocas de chuva intensa, tornando a população residente do local mais vulnerável a esses eventos extremos. A distribuição dos domicílios que não tem coleta de lixo na região é apresentada na Figura 4.

Campina Grande apresenta-se como o município com mais domicílios sem coleta de lixo (5.775 domicílios, correspondendo a 5,2\% do total de domicílios), seguido por Queimadas (3.699 domicílios, correspondendo a 30,8\% do total de domicílios). O município com a menor quantidade de domicílios sem coleta de lixo foi Riacho de Santo Antônio, apresentando 146 domicílios nessa condição, 30,8\% do total de domicílios do município.

A média de domicílios sem coleta de lixo encontrada foi de 1.322. A grande quantidade de domicílios em Campina Grande (5.775 domicílios) novamente influenciou no alto valor da média, apesar desse valor encontrado da cidade representar apenas 5,2\% do total de domicílios que não possuem coleta de lixo. A região leste abrangeu novamente os valores mais altos da variável analisada, fato a ser explicado pela presença de municípios mais populosos como Campina Grande e Queimadas. 
Figura 4 - Mapa dos domicílios sem coleta de lixo na Região Geográfica Imediata de Campina Grande

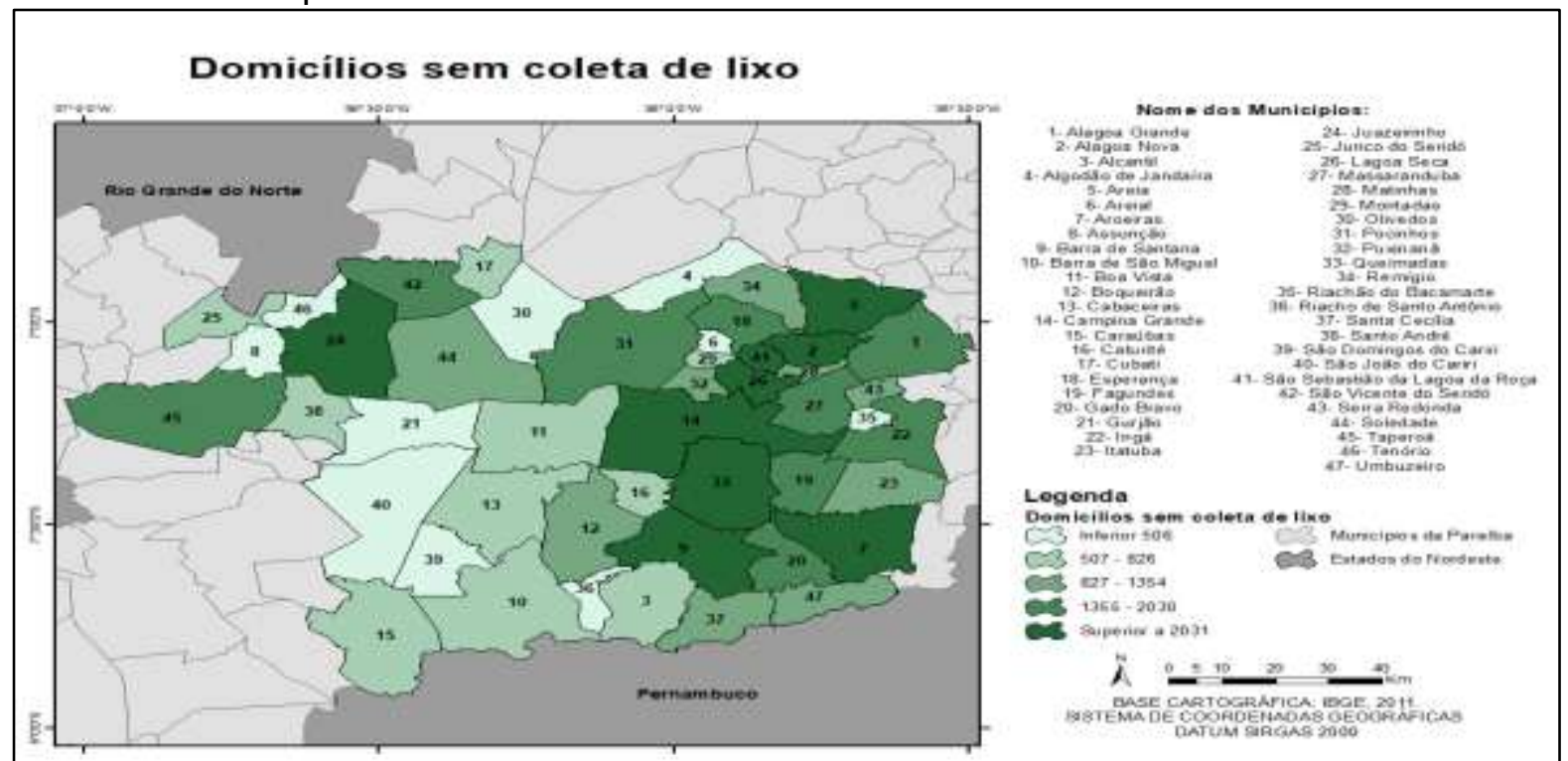

Fonte: organizado pelos autores de IBGE (2011).

Em municípios do interior é muito comum que o lixo seja recolhido por carroças, sem nenhuma forma de segurança para os trabalhadores. Os resíduos também são levados para lixões, devido ainda a ausência de aterros sanitários. Outra solução encontrada é a queima do lixo, o que não se mostra uma alternativa correta devido às emissões de gases tóxicos, degradando o meio ambiente.

A presença da energia elétrica é um fator de infraestrutura básico e a ausência dela reflete a precariedade de serviços no local. Caso ocorra um desastre ocasionado por fenômenos naturais, a falta de energia elétrica irá influenciar na reação imediata e na recuperação básica da população, por isso é um fator a se considerar na análise do risco social, além de ser um bom indicador de pobreza, já que o setor elétrico é um serviço privado. A distribuição dos domicílios sem energia elétrica na região é apresentada na Figura 5.

A região leste do mapa se destaca pela maior concentração de municípios com maior quantidade de domicílios sem energia elétrica. Novamente, Campina Grande apresentou o maior valor (244 domicílios). O município com menor quantidade de domicílios sem energia elétrica foi Olivedos, com apenas três domicílios desprovidos de energia elétrica. A média encontrada foi de 35 domicílios sem energia elétrica. Vale ressaltar que 32 municípios tiveram um resultado abaixo da média.

A pobreza e a desigualdade se relacionam de forma intrínseca, onde a falta de acesso a uma educação básica repercute diretamente no ingresso no mercado de trabalho, afetando proporcionalmente a renda e a condição de vida da população mais pobre. No Brasil, as regiões que apresentam maiores taxas de analfabetismo são também as mais 
pobres do país, comprovando essa relação. A má qualidade da educação pública no país ocasiona muitas vezes a estagnação dos alunos nas séries primárias, destacando-se a grande quantidade de reprovações. Outro fator importante é a dificuldade de permanência nas escolas, porque devido às condições socioeconômicas em que se encontram muitos dos alunos abandonam os estudos para trabalhar.

Figura 5 - Mapa dos domicílios sem energia elétrica na Região Geográfica Imediata de Campina Grande

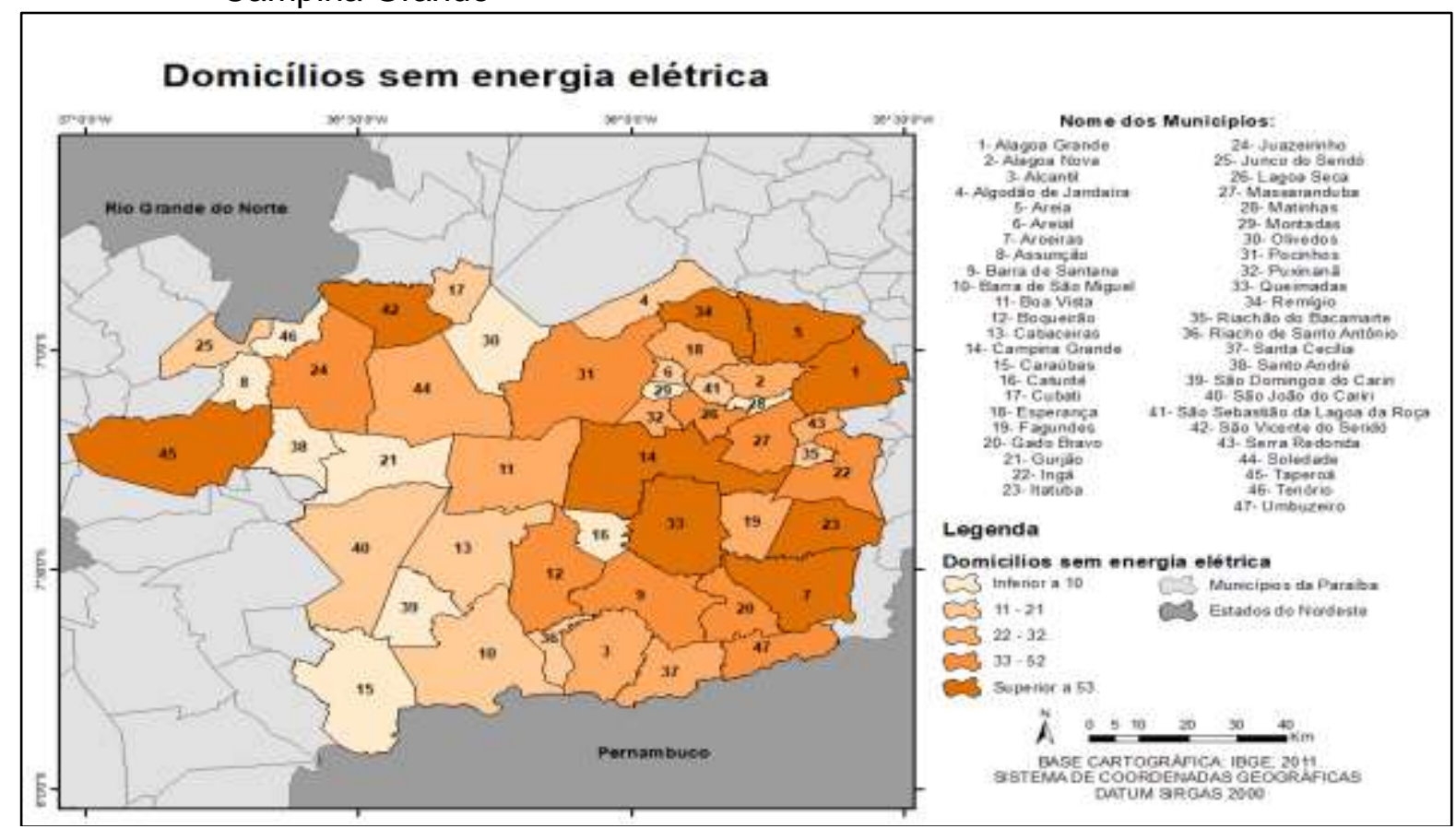

Fonte: organizado pelos autores de IBGE (2011).

De modo geral, o analfabetismo em responsáveis por domicílios repercute na dificuldade de qualificação, o que ocasiona um crescimento na procura por atividades pouco remuneradas, destacando as atividades informais. Devido a essa dificuldade de inserção no mercado de trabalho, essas pessoas não conseguem adquirir condições financeiras suficientes para morar em lugares que oferecem uma boa qualidade de vida, serviços de saneamento básico e saúde ambiental adequada.

O nível de instrução, além de influenciar diretamente na qualificação da população - o que afeta nas oportunidades e consequentemente na renda - é um fator que interfere na percepção dos riscos, devido ao acesso a informação.

A distribuição de pessoas analfabetas acima de cinco anos de idade e a distribuição dos domicílios com rendimento mensal abaixo de um salário mínimo na Região Imediata de Campina Grande é apresentada na Figura 6 e 7.

A área leste da região apresentou a maior quantidade de população analfabeta e também a maior quantidade de domicílios que possuem renda per capita mensal abaixo de um salário mínimo. A média obtida para a população analfabeta foi de 4.980 analfabetos. 0 
total de 34 municípios apresenta uma quantidade de habitantes analfabetos abaixo da média, o que acontece devido à presença de municípios com uma maior quantidade de habitantes, que acabam elevando o valor da média.

Figura 6 - Mapas da população analfabeta na Região Geográfica Imediata de Campina Grande

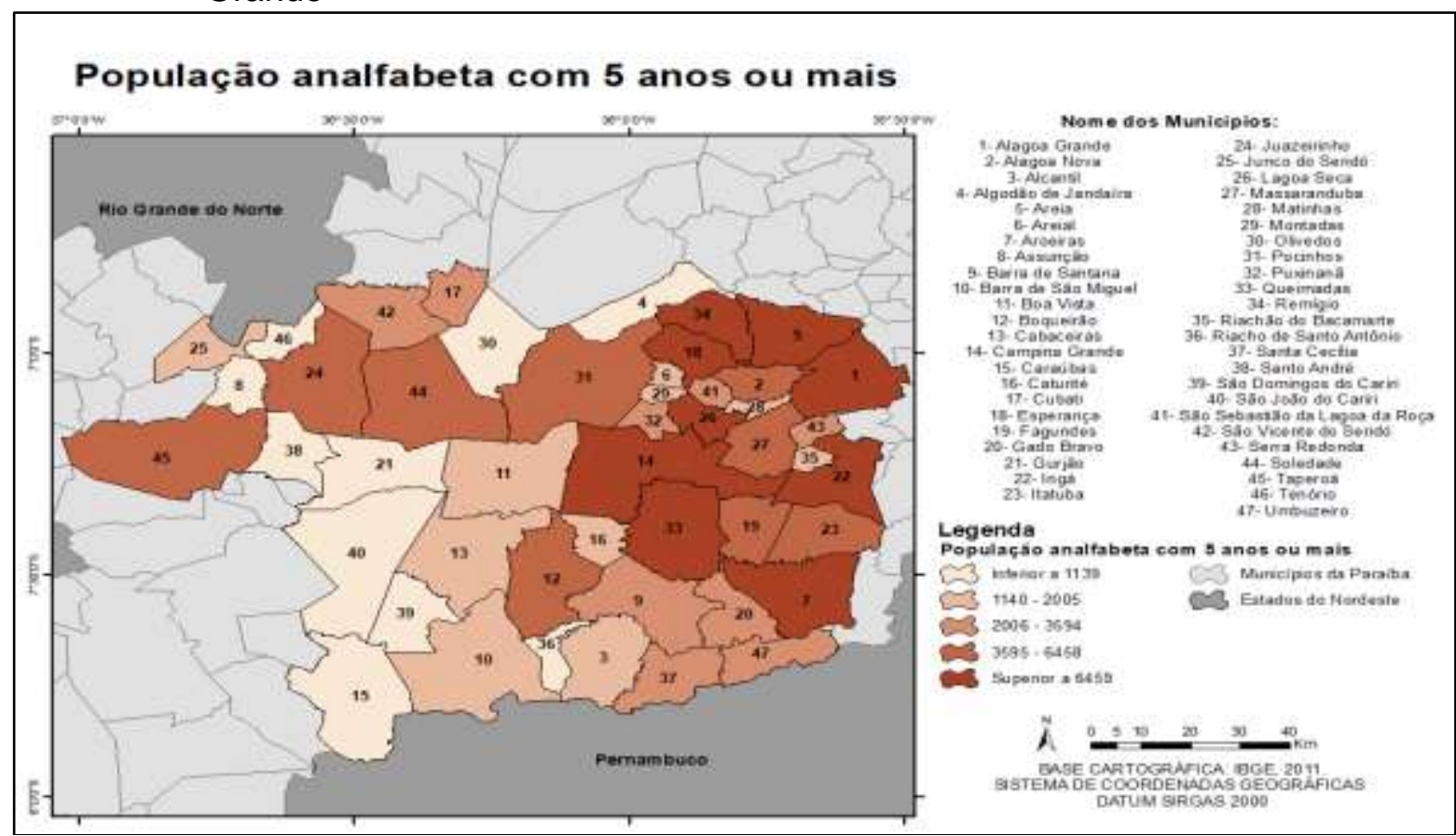

Fonte: organizado pelos autores de: IBGE (2011).

O mesmo comportamento foi observado em relação à quantidade de domicílios que possuem renda inferior a um salário mínimo. O valor da média foi 4.215, e 38 municípios apresentaram valores inferiores a este.

Aproximadamente 58\% dos municípios de pequeno porte da região, abaixo de 10.000 habitantes, possuem mais de $30 \%$ da sua população analfabeta. Dos municípios com uma população superior a 10.000 habitantes, 66,67\% apresentam mais de $30 \%$ da sua população analfabeta. A relação do analfabetismo é bem heterogênea na região, majoritariamente com valores acima de $30 \%$, fator preocupante considerando a proporção da quantidade de analfabetos e do total de habitantes nos municípios.

$O$ analfabetismo reflete diretamente na percepção dos riscos e pode resultar também na baixa capacidade de resiliência. A resiliência é um termo importante a se considerar no contexto da região estudada porque está vinculada a épocas de seca intensa e duradoura que ocorrem em diversos municípios da região. Holling (1973) afirma que o conceito de resiliência possibilita a avaliação da capacidade de um sistema de enfrentar e se recuperar de choques, seja por meio da capacidade de absorção e também reorganizando os seus componentes visando chegar em um estado de equilíbrio. Com relação aos desastres naturais, o conceito de resiliência se refere a ótica da adaptabilidade, ou seja, a habilidade 
Risco Social na Região Imediata de Campina Grande: subsídios para a compreensão das condições...

dos sistemas de se adaptar, a capacidade de resistir, se recuperar e se reorganizar após um desastre.

Figura 7 - Mapa dos domicílios com renda per capita inferior a um salário mínimo na Região Geográfica Imediata de Campina Grande

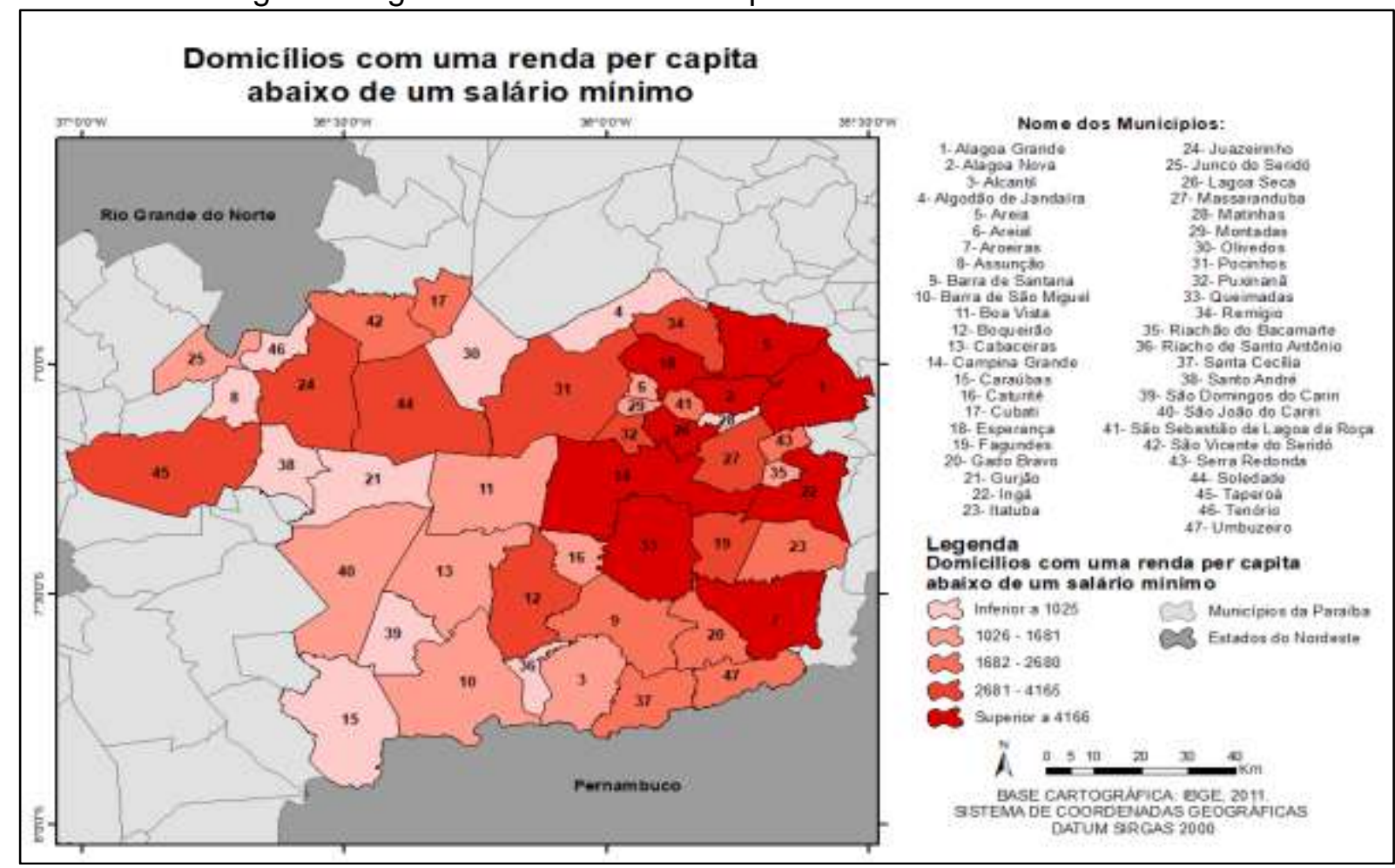

Fonte: organizado pelos autores de: IBGE (2011).

A seca que se iniciou em 2012 foi a pior seca já registrada na região, afetando diretamente a economia vinculada a atividades de agricultura, principalmente aos produtores que praticam agricultura de baixo custo. Por se tratar de um desastre cuja evolução é gradual, há uma grande preocupação com a perspectiva de períodos mais longos e severos de secas nos próximos anos, o que mostra a urgência de direcionar incentivos na gestão de riscos e desastres, de forma a elaborar planos de prevenção.

Diferentemente do desastre gradual que é a seca, que permite a elaboração de estratégias de convivência com esse fenômeno, desastres súbitos como inundação, enchentes, alagamentos, deslizamentos de terra, potencializados pelas chuvas intensas características da região, também são uma preocupação por acontecerem de forma aguda, surpreendendo a população. A vulnerabilidade de um grupo social é em função do grau de exposição, proteção, reação imediata, recuperação básica e reconstrução. As perdas ocasionadas por esse tipo de desastre são mais acentuadas em populações de baixa renda, visto que a proteção do sistema é mais falha, devido à infraestrutura inadequada e serviços precários, além de que o processo de recuperação será mais lento e difícil devido às baixas condições financeiras que essa parcela da população apresenta. 
Levando em conta todas as informações obtidas por meio dos mapas, onde foram avaliadas as seis variáveis aqui mencionadas, foi então calculado o risco social dos municípios da Região Imediata de Campina Grande (Figura 8).

Figura 8 - Mapa do risco social da Região Geográfica Imediata de Campina Grande

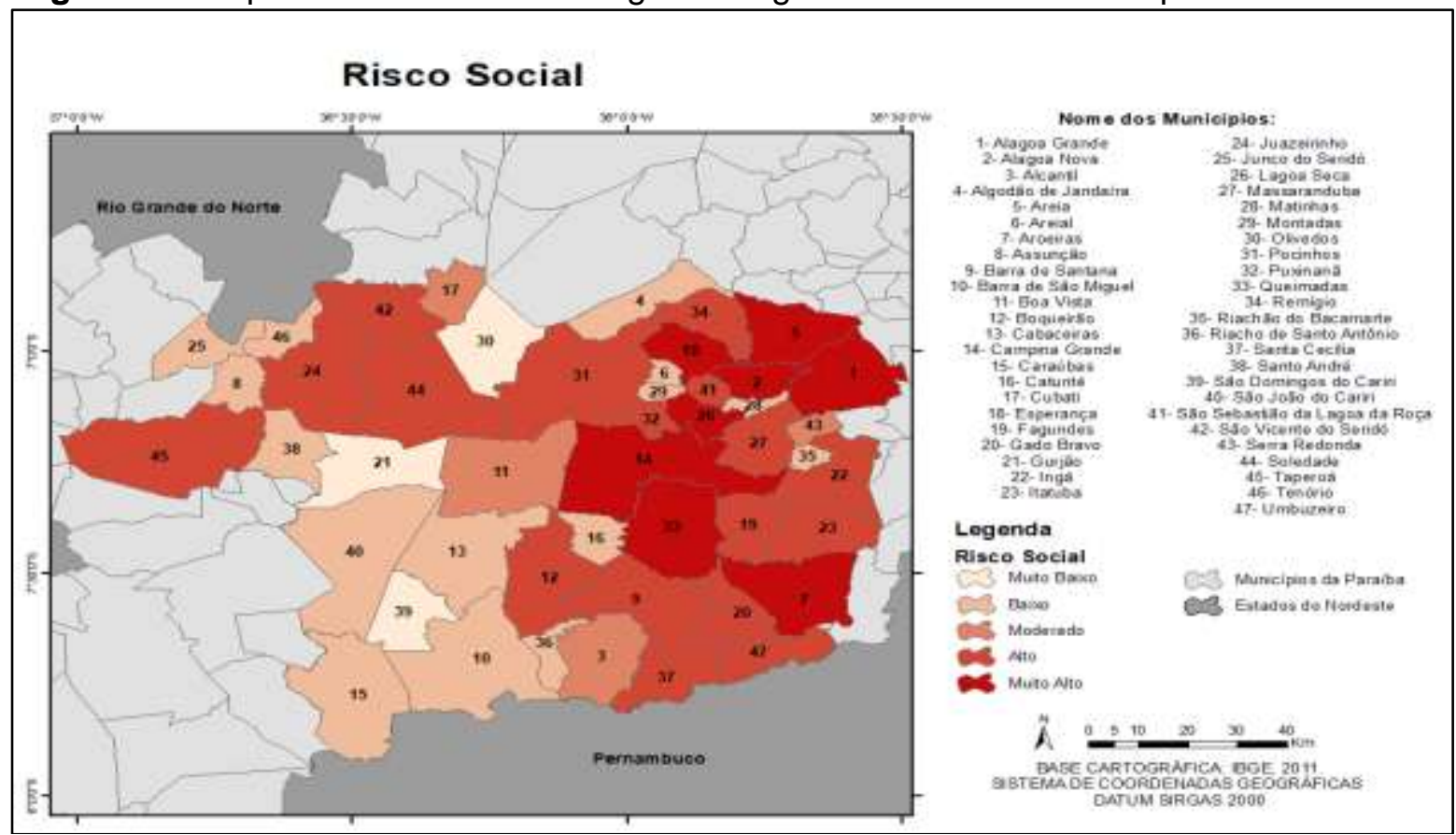

Fonte: organizado autores com base na pesquisa, ano de 2017.

Oito municípios apresentaram um risco muito alto, sendo eles: Queimadas, Lagoa Seca, Campina Grande, Aroeiras, Areia, Esperança, Alagoa Nova e Alagoa Grande, todos eles localizados na parte leste da região. De forma geral, municípios com o risco social mais elevado se concentram majoritariamente nessa porção, com destaque para alguns municípios ao norte que também estão inseridos.

A presença de municípios mais populosos na parte leste favorece essa concentração, como Campina Grande, Queimadas, Alagoa Grande, Lagoa Seca, Esperança e Areia. Por possuírem maior quantidade de habitantes consequentemente apresentam um maior número de domicílios. Não necessariamente esses municípios apresentam as piores condições caso fossem tratados individualmente, mas levando em conta a média, estão inseridos numa área com a maior concentração de municípios com alto a muito alto risco social. Algodão de Jandaíra, Caturité, Matinhas, Montadas, Riachão de Bacamarte e Areial são os únicos municípios dessa área leste que apresentam um risco social baixo - nenhum município apresentou risco muito baixo nessa parte da região.

Vale salientar que a parte leste apresentou as piores condições de entorno e a maior parcela da população analfabeta. Ainda se observou nessa área a maior parte de domicílios 
Risco Social na Região Imediata de Campina Grande: subsídios para a compreensão das condições...

que possuem uma renda per capita abaixo de um salário mínimo, fator relevante para entender a situação de pobreza e privação em que se encontram essas pessoas.

A parte sul da região apresenta municípios com um risco social menor, porém deve ser levado em conta que esses municípios apresentam uma quantidade de habitantes demasiadamente inferior em relação aos municípios da parte leste, como Riacho de Santo Antônio (1.713 habitantes), São Domingos do Cariri (2.420 habitantes), Caraúbas (3.881 habitantes) e Barra de São Miguel (5.604 habitantes).

A parte oeste caracteriza-se pela maior concentração de municípios com o risco social muito baixo e baixo, apenas com exceção para Taperoá, Juazeirinho, Soledade e São Vicente do Seridó que apresentam um alto risco social. Pocinhos encontra-se numa área mais central da região, possuindo um risco social alto. Esses municípios apresentam mais de 10.000 habitantes, diferentemente da maioria dos municípios dessa parte oeste, fato que influencia na média estabelecida para as variáveis em comparação com os municípios de menor porte.

Apenas quatro municípios apresentaram um risco moderado, um deles localizando-se ao leste (Serra Redonda), um no centro (Boa Vista), um ao oeste (Cubati) e o outro ao sul (Alcantil).

Santa Cecília, Barra de Santana, Gado Bravo e Umbuzeiro são municípios predominantemente rurais, com menos de 10.000 habitantes e apresentam um risco social alto. Levando em consideração que a média foi elevada pelos municípios com um maior número de habitantes, municípios pequenos apresentarem um risco alto é um fator preocupante.

Em resumo, destaca-se que os municípios com maior risco social foram aqueles em que os indicadores sociais e econômicos do estudo foram mais expressivos. Os municípios com muito alto risco social também apresentaram os valores mais elevados nas variáveis que tinham como intuito indicar as condições de infraestrutura e de privação social em que a população se encontrava.

A presença de uma cidade do porte de Campina Grande na área de estudo, visto a sua importância econômica para o estado, e que apresenta uma diferença significativa em número de habitantes para os demais municípios, deve ser levado em consideração para avaliar a região de forma abrangente. Mais da metade dos municípios da região são predominantemente rurais, onde a economia é duramente afetada pela seca. A maioria dos municípios, mais distante dos centros urbanos, também tem grave problema com 0 abastecimento de água, devido à escassez de água da região e ainda há a presença de águas subterrâneas salobras, sendo necessária a busca por alternativas para abastecimento. 
A construção do risco na Região Geográfica Imediata de Campina Grande está atrelada a níveis de exposição, resistência e resiliência que interferem na vulnerabilidade dos grupos sociais residentes, fruto de um contexto social, político e econômico. Por ser uma região que enfrenta duramente longos períodos de seca, as dificuldades permanecem presentes apesar da recorrência desse fenômeno, destaca-se a ineficiência na gestão pública e a falta de planos de contingência. Por ser caracterizado pela falta de recursos e medidas emergenciais em lidar com a falta de água (secas e estiagens) e excessos de água (enchentes, alagamentos, deslizamentos e escorregamentos causados por fortes chuvas) é um local que enfrenta difíceis situações quando esses eventos ocorrem, onde a população mais pobre é sempre a mais afetada.

Vale observar ainda que a determinação do risco social foi feita em escala regional, tendo os municípios como unidades de análise. Utilizar a escala intraurbana, por meio da avaliação dos setores censitários, interferiria na interpretação dos resultados, pelo fato de considerar informações que são generalizadas ao se utilizar uma escala regional. Como exemplo, poderiam ser encontradas áreas de risco alto dentro de um município que obteve risco baixo neste estudo.

A análise intraurbana possibilitaria aos gestores o desenvolvimento de políticas públicas de planejamento no contexto municipal, motivando a intervenção pública nos locais que necessitam de suporte e que estão inseridas num quadro de risco social elevado. $O$ emprego da escala regional pode oferecer uma visão abrangente da Região Geográfica Imediata de Campina Grande, apontando municípios que podem estar enquadrados em situações de risco, contribuindo para avaliações individuais nos setores censitários dos municípios em etapas posteriores.

Outro fator relevante é que a futura agregação ao presente trabalho do viés ambiental, considerando variáveis que permitam realçar o risco ambiental na região, contribuirá para a compreensão da vulnerabilidade socioambiental. A interpretação da vulnerabilidade permitirá melhor assimilar a situação da Região Imediata de Campina Grande, apontando as frações que necessitam de ações mais urgentes do poder público em relação à prevenção de desastres.

\section{CONSIDERAÇÕES FINAIS}

Esse trabalho buscou realizar o mapeamento do risco social na Região Imediata de Campina Grande, a partir da integração de indicadores sociais e econômicos da população, além do acesso a serviços de infraestrutura básicos. Futuramente, pretende-se integrar mais variáveis no estudo, como quantidade de idosos e crianças. Ainda pretende-se avaliar o risco ambiental, para então avaliar a vulnerabilidade socioambiental dessa região. 
Risco Social na Região Imediata de Campina Grande: subsídios para a compreensão das condições...

A porção da região que apresentou maior risco social foi a região leste. A concentração de domicílios nessas condições na parte leste pode ser justificada pela presença de municípios urbanos com maior população nessa área. Já a área oeste se mostrou bastante heterogênea, tanto em termos de risco social, quanto em termos das variáveis tratadas individualmente. Esse fato também se deve a variável população que se apresenta nessa parte da região, exibindo municípios que possuem uma população abaixo de 10.000 habitantes e outros com população acima desse valor.

Os indicadores que foram mapeados no presente estudo podem ser parâmetros para entender e contextualizar a qualidade da moradia da população, avaliando a infraestrutura e as condições sociais a que ela está submetida. Essas informações, quando tratadas em escala intraurbana, podem motivar intervenções públicas nos locais e também incentivar o desenvolvimento de políticas públicas de planejamento urbano que minimizem as desigualdades.

O mapeamento de áreas de risco social, portanto, tem a função de proporcionar informações sobre a realidade local, sendo uma ferramenta para apontar caminhos que devem ser traçados e medidas que devem ser tomadas, de modo que os responsáveis possam construir os mecanismos que devem ser realizados para atenuar o problema que pode ser agravado caso ocorra um evento extremo. Futuramente espera-se que, ao passo que mais variáveis forem integradas no estudo dessa região, mais informações sejam disponibilizadas para subsidiar decisões dos responsáveis pela gestão de riscos e desastres.

\section{REFERÊNCIAS}

ALVES, H. P. F. Análise da vulnerabilidade socioambiental em Cubatão-SP por meio da integração de dados sociodemográficos e ambientais em escala intraurbana. Revista Brasileira de Estudos de População, Rio de Janeiro, v. 30, n. 2, p. 349-366, jul./dez. 2013.

ALVES, H. P. F. TORRES, H. G. Vulnerabilidade socioambiental na cidade de São Paulo: uma análise de famílias e domicílios em situação de pobreza e risco ambiental. São Paulo em Perspectiva, São Paulo, v. 20, n. 1, p. 44-60, jan./mar. 2006.

ALVES, H. P. F. Vulnerabilidade socioambiental na metrópole paulistana: uma análise sociodemográfica das situações de sobreposição espacial de problemas e riscos sociais e ambientais. Revista Brasileira de Estudos da População, São Paulo, v. 23, n.1, p. 43-59, jan./jun. 2006.

BRASIL. Lei Federal 12.305, de 2 de agosto de 2010. Institui a Política Nacional de Resíduos Sólidos; altera a Lei no 9.605, de 12 de fevereiro de 1998; e dá outras providências. Disponível em: <http://www.planalto.gov.br/ccivil_03/_ato20072010/2010/lei/l12305.htm>. Acesso em: 21 mar. 2018.

EGLER, C. A. G. Risco ambiental como critério de gestão do território: uma aplicação à zona costeira brasileira. Território, Rio de Janeiro, v. 1, n. 1, p. 31-41, 1996. 
GUIMARÃES, P. R. B. Medidas de Posição e Variabilidade. In: quantitativos estatísticos. Curitiba: IESDE Brasil, 2008. p. 49-55.

Métodos

HOLLING, C. S. Resilience and stability of ecological systems. Annual Review of Ecology and Systematics, Palo Alto, v. 4, n. 1, p. 1-23, 1973.

IBGE. Base de informações do censo demográfico 2010: resultados do universo por setor censitário. Rio de Janeiro, 2011.

IBGE. Cidades. Campina Grande. 2017a. Disponível em: <https://cidades.ibge.gov.br/brasil/pb/campina-grande/panorama>. Acesso em: 2 fev. 2017.

IBGE. Classificação e caracterização dos espaços rurais e urbanos do Brasil: uma primeira aproximação. Rio de Janeiro, 2017b.

IBGE. Divisão regional do Brasil em regiões geográficas imediatas e regiões geográficas intermediárias: 2017. Rio de Janeiro, 2017c.

LAVELL, A. Gestión de Riesgos Ambientales Urbanos. Red de estudios sociales em prevención de desastres em América Latina. Lima: La Red, 1999. Disponível em: <http://www.desenredando.org/public/articulos/1999/grau/>. Acesso em: janeiro de 2018.

MARENGO, J. A. Vulnerabilidade, impactos e adaptação à mudança do clima no semiárido do Brasil. Parcerias Estratégicas, Brasília, n. 27, p. 149-174, dez. 2008.

MENDONÇA, M. J. C.; MOTTA, R. S. Saúde e Saneamento no Brasil. Planejamento e Políticas Públicas, Brasília, v. 30, p. 15-30, jun./dez. 2007.

OLIVEIRA, E. M. et. al. Desertificação e seus impactos na região semiárida do Estado da Paraíba. Ambiência, Guarapuava, v.5, n.1, p.67-79, jan./abr. 2009.

PARAÍBA. Instituto de Desenvolvimento Municipal e Estadual. Secretaria de Estado do Planejamento, Orçamento e Gestão. Produto interno bruto dos municípios do Estado da Paraíba: 2014. João Pessoa: IDEME, 2016. Disponível em:

<http://static.paraiba.pb.gov.br/2017/07/nota-tecnica_pib-municipal_2014.pdf>. Acesso em: 2 fev. 2017.

RIBEIRO, T. C. S. C. Métodos tabulares e métodos gráficos. In: Probabilidade e estatística. Londrina: Educacional, 2015. p. 73-117.

TORRES, H. G. Desigualdade ambiental na cidade de São Paulo. 1997. Tese (Doutorado em Ciências Sociais) - Instituto de Filosofia e Ciências Humanas, Universidade de Campinas, Campinas.

TORRES, H. G. et. al. Pobreza e espaço: padrões de segregação em São Paulo. Estudos Avançados, São Paulo, v. 17, n. 47, p. 97-128, 2003.

UNIVERSIDADE FEDERAL DE SANTA CATARINA. Centro Universitário de Estudos e Pesquisas sobre Desastres. Atlas brasileiro de desastres naturais 1991 a 2010: volume Paraíba. Florianópolis: CEPED UFSC, 2011.

VEYRET, Y. Os riscos: o homem como agressor e vítima do meio ambiente. São Paulo: Contexto, 2007. 